\title{
Remanufacturing: a potential sustainable solution for increasing medical equipment availability
}

\author{
Solomon Eze ${ }^{1}$ (D) $\cdot$ Winifred ljomah ${ }^{1}$ - T.C. Wong ${ }^{1}$
}

Received: 13 November 2018 / Accepted: 3 April 2020 / Published online: 25 April 2020

(C) The Author(s) 2020

\begin{abstract}
The availability of medical equipment contributes significantly to the stability and sustainability of health care systems. However, in some countries, especially the developing ones, medical equipment availability is a major issue that remains unsolved. Hence, this paper explores the root causes of the issue, reviews existing solution approaches and suggests remanufacturing as a sustainable option. An extensive review was first conducted to uncover key factors contributing to the poor availability of medical equipment in developing countries. The Decision-Making Trial and Evaluation Laboratory (DEMATEL) method was then used to measure the prominence degrees of the key factors and characterise these factors with an aim to differentiate those that are net drivers from those that are driven. Subsequently, factors that can be addressed by remanufacturing were identified, to determine the potential contribution of remanufacturing in addressing the poor medical equipment availability issue. The result shows that remanufacturing can potentially address at least five of the key factors which account for a cumulative total prominence of $43.5 \%$. Remanufacturing is thus, a viable strategy for improving medical equipment availability in developing countries. In addition to remanufacturing, other recommendations were also proposed to help address the issue.
\end{abstract}

Keywords Medical equipment $\cdot$ Remanufacturing $\cdot$ DEMATEL $\cdot$ Medical equipment availability

\section{Introduction}

Medical equipment are reusable medical devices that are durable, expensive, complex, maintainable/repairable and which often require user training, calibration and

Solomon Eze

Solomon.eze@ strath.ac.uk

1 Design, Manufacture and Engineering Management, University of Strathclyde,

Glasgow, Scotland, UK 
decommissioning are referred to as medical equipment [48]. According to the World Health Organisation [61], medical equipment do not include implantable, disposable or single use devices. Their availability is associated with improved patient outcomes. Thus, healthcare administrators seek innovative means of optimising its supply [56], However, providing access to medical equipment can be difficult for some countries such as those facing extreme austerity; among which developing countries are typical examples. Remanufacturing seems to be a potential solution but has not been previously considered. Remanufacturing is the process of restoring a used product to at least, its original equipment manufacturer's performance specification from the customer's perspective and giving the resultant product a warranty that is at least equal to that of newly manufactured equivalent product [64]. This study estimates the potential impact of remanufacturing in addressing medical equipment availability issues in developing countries.

Developing countries are those categorised by the World Bank as low and middleincome earners [4]. For many of these countries, it is difficult to access medical equipment necessary for healthcare even though they are indispensable to the diagnosis, prevention, monitoring and treatment of disease and injury. This challenge is important, considering that about $85 \%$ of the world's population reside in developing countries which account for just $15 \%$ of global market for medical equipment [6, 60]. Consequently, the healthcare quality in developing countries is poor, resulting in high mortality rates over conditions that would otherwise be easy to treat and manage if the right equipment were available. For instance, over the globe, 2.6 million neonatal deaths, 2.8 million still births and over 287,000 maternal deaths were recorded in 2009. About $99 \%$ of these deaths occurred in developing countries often due to lack of complex medical equipment such as diagnosis equipment which cause delayed advising and referral [16]. Previous studies [1, 8, 32, 45, 58, 70] comment on the factors responsible for the problem without aiming to explore their interrelationships. They propose solutions from perspectives that are often either isolated or not based on holistic approach. By analysing the factors, taking account of interdependencies among them; this paper aims to determine the applicability of remanufacturing in addressing the problem of poor access to medical equipment.

\section{Review of related literature}

\section{Current approaches to addressing poor availability of medical equipment}

Due to the grave consequences of poor access to medical devices in developing countries, several efforts have been implemented to address the problem. These include the following:

- Medical equipment donation from government and non-governmental organisations abroad $[2,17,34,43,59,61,67]$.

- Design of low cost medical equipment for developing countries [27, 36, 37, 47].

- Use of imported refurbished medical devices [17].

- Promotion of local production $[4,65]$.

Local production of medical equipment is desirable since it can potentially make medical equipment more available and sustainable in any given setting. However, it is 
not an easy alternative for developing countries due to the advanced technological requirements of modern manufacturing [23] which are often unavailable in many developing countries. The challenges associated with the other approaches are discussed in the following sections.

\section{Challenges of medical equipment donations to developing countries}

Medical equipment donations usually come from developed countries' governments, charity organisations, hospitals, health clinics and educational organisations [2, 62]. Donations may be motivated by genuine intentions. However, some donors may have some indirect financial motivation. For instance, a study of medical equipment donations from Canada found that financial incentives from manufacturers of medical equipment to hospitals that dispose of their used equipment themselves may motivate medical equipment donations [2].

Major destinations of medical equipment from international donors include Malawi, India, Pakistan, Somalia, Sri-Lanka, Nigeria, Philippines, Syria, Uganda, Cuba and Cameroun [17]. Developing countries' hospitals usually engage the services of non-profit or charity organisations to source for potential donors in order to avoid the legal rigours associated with medical equipment donations especially due to the restricted trans-border movement [2].

Reports about the utility of donated equipment suggest that only few of them actually become useful to the recipients $[43,59,61]$. In view of this, the World health organisation consistently makes efforts to rationalise medical equipment donation so that recipient countries can derive utility from them. The first draft guideline towards this objective became available in 2000 and was subsequently updated in 2011 [61]. The Tropical Health Education Trust (THET) also has a publication titled: "Toolkit for medical equipment donations to low resource settings" aimed at improving the donation process especially for the poorest countries that rely almost entirely on it.

The three government agencies in the recipient country that are often involved in receiving donated equipment are the Ministry of Health, Ministry of Commerce and Customs [17] . But in practice, only the Customs and Commerce get involved for tax clarifications; the use of many donated medical equipment therefore, commences before proper acceptance or quality assurance testing. Thus, donated equipment are not usually subjected to post donation inspection and certification of quality [69]. This results in equipment which often do not pass quality tests. A study of a Tanzanian hospital staff's perceptions of donated medical equipment shows that $78 \%$ of participants were discontented with the equipment. The most important reasons given by these discontented respondents are lack of technical support and specifications crucial to the use of the equipment [69].

If a donation solicitor decides to be careful to ensure that only the right equipment are transferred to recipients, then the more complex equipment will usually not be accepted due to lack of expertise needed to repair or maintain them [17]. This consideration would subject the people in the recipient country to a limited supply of the more sophisticated medical equipment needed in health care. This implies that a sustainable solution to medical equipment availability in developing countries should provide sustained access to the equipment through promotion of commercial activities required to avail spare parts, accessories, consumables and technical support services. Obviously, medical equipment donations fall short on these requirements. Consequently, medical equipment donation may only be a temporary measure. 


\section{The downside of designing low cost medical equipment for developing countries}

According to Eltringham and Neighbour $[12,13]$, claims that low cost medical equipment designs can address the medical equipment availability issues in developing countries raise several important questions. Firstly, the author notes that the so-called low-cost equipment are in reality, subsidised since the cost of development which is usually in the form of grant to the research institutions are often ignored. Secondly, the author emphasises that the principle of low-cost design is usually based on the use of lowquality components or improvising to make the final product's price less than its equivalent in the market. Limiting the functionality of an equipment in a bid to making it less expensive may however, have moral and ethical implications.

Eltrinhham and Neighbour also observe that only a few of the so called low cost or subsidised product designs become successfully developed eventually and these are supplied to developing countries through non-commercial means [13]. Moreover, since the institutions carrying out the design and manufacture of the devices do not usually have a commercial base or route to the market, the authors note that they are likely to go out of business as soon as the funding ceases, leaving users of the equipment without technical support necessary for their sustained utilisation. Thus, it is vital to supply medical equipment to developing countries through indigenous resellers, agents and suppliers as this approach will enhance commercial activities and sustainability by providing local skill sets and spare parts for maintenance.

\section{Direct reuse of medical equipment or reuse of repaired/ refurbished equipment}

Medical equipment value chain should not terminate at post sales services or end of life which marks the point where the products are discarded due to technological obsolescence, deterioration or change in consumer preferences. It is conceivable that medical devices that reach their end of life (EOL) for instance, due to change in user's preference (such as decision to opt for a more innovative technology) would have the majority of their components good enough to extend the product's life or even to sustain it through another lifecycle. Instead of disposing products, at this stage, an EOL strategy may be applied to extend or renew their utility. EOL strategies refer to the different ways of recovering products with differing levels of reuse. These strategies mitigate environmental impacts and add economic benefits to product disposal $[19,49]$ and include the following [46]:

- Direct reuse.

- Repair.

- Use of reprocessed medical devices. Reprocessed devices include the following [41]:

- Refurbished devices

- Remanufactured / fully refurbished devices (Term used in Europe) devices

EOL processes vary in terms of quality as well as price of the resultant products. Repair involves reworking or replacing only damaged components without aiming to restore the product to its original specification [22]. In refurbishment, the used product is reprocessed such that its performance is returned to limits considered acceptable for 
reuse [41]. However, remanufacturing yields a product which at least, equals an equivalent new one in terms of performance specifications and warranty. Both a whole product and sub-assemblies can be remanufactured [22]. In order to determine the applicability as well as the potential impact of implementing medical equipment remanufacturing, it is necessary to first explore the factors responsible for the poor availability of medical equipment.

\section{Root causes of poor availability of medical device in developing countries}

The poor availability of medical equipment in developing countries is caused by several key factors and has been widely studied $[1,18,30,43,57,68]$. In this section, these factors are presented as identified from the literature.

\section{Corruption}

According to Bouchard [8], corruption in healthcare organisation contributes significantly to the problem. The authors found that corruption within the health care industry usually takes the form of inflation of equipment prices, purchase of lower quality equipment and products as well as lowering of care quality which ultimately resist the necessary response to alleviating health care challenges.

\section{Lack of funds}

Lack of funds is an important factor causing the poor availability of medical devices in developing countries. Many developing countries do not have sufficient funds to acquire necessary equipment $[32,39,45]$. The people are also unable to pay for expensive lifesaving procedures [11]. Thus, poverty, illness and disability are related [11].

\section{Lack of robust regulation, HTA and HTM}

The World Health Organisation recognises the need for poorer countries to have stronger regulations as well as health technology assessment and management policies in place to optimise medical equipment procurement and use [62]. However, this is often not the case [10, 38, 43, 57]. Health Technology Assessment (HTA), Health Technology Management (HTM) and Regulatory units should collaborate to achieve their objectives. HTA supports evidence based decision-making preceding the acquisition of new technologies [62]. This is necessary to ensure that proposed new technologies are those that will be effective, appropriate and implementable towards advancing health care quality.

HTM also known as clinical engineering carries out planning, needs-assessment, selection, procurement, inventory, installation and maintenance of medical equipment as well as training and decommissioning [28, 62] The tasks associated with each element include technical advice, planning and costing, supply chain, disposal and record keeping. A study finds that available medical equipment in developing countries can be doubled just by implementing HTM [43].

\section{Inappropriateness of available equipment}

The implication of weak or absent HTA, HTM and regulation include lack of standards and abundance of sub-standard equipment or those that do not contribute 
to healthcare. Thus, much of the medical equipment in developing countries are not useful in addressing prevailing disease burden. This is because some medical equipment commonly found in developing countries are those that are not designed for the prevailing needs $[18,57]$. Because medical equipment procurement is largely uncoordinated, products from a wide variety of manufacturers are available. Under such circumstance, it becomes difficult for the technicians to gain the proficiency necessary to maintain the available equipment varieties. This ultimately challenges the sustainability of medical equipment in developing countries [7].

\section{Lack of skilled workers}

According to Malkin [30], technicians were found to have inadequate skills and users have poor understanding of how to use medical equipment. Consequently, equipment damage becomes frequent leading to the disrepair states of many medical equipment [43]. Due to lack of skilled workers, functional equipment may also be classified as damaged. For instance, a study of 1704 documented failed medical equipment finds that $25 \%$ of the equipment classified as failed were actually in good working order [31].

\section{Lack of spare parts}

Equipment may be unavailable in developing countries because of lack of spare parts $[5,55]$. This causes both delay in carrying out procedures and an upward push in the total cost of ownership of medical equipment [29]. Also, many of the available medical equipment are obsolete [38] and as a result, their production by their manufacturers may have been discontinued. In such cases, there would be only a minimal chance of successfully repairing the equipment due to lack of access to spare parts.

\section{Lack of economic model}

Hospitals in developing countries often do not aim to minimise costs by for instance, making use of a technology only when it is absolutely necessary or minimising the duration of hospital stay [26, 43]. Malkin also notes that the poor availability of medical equipment in developing countries may not be so much about poverty since there are already medical equipment whose maintainability are usually not sustained [33] but due to lack of economic models.

\section{Poor infrastructure}

Other causes of poor availability of medical equipment in developing countries include lack of infrastructure such as electricity and oxygen [14, 45, 47]. For instance, the use of modern technology usually requires stable and reliable supply of electricity as well as electronic devices and the internet; these are not available in many developing countries [17].

\section{Unreliable supply chain communication}

Most medical equipment are manufactured outside developing countries; necessitating well-coordinated supply chains to acquire consumables and spare parts. This is usually not available [35, 47, 69]. 


\section{Workers' attitude}

In some cases, clinical staff may refuse to use an equipment if they consider them difficult or inconvenient and may even declare them damaged [45].

The causes of poor medical equipment availability in developing countries are numerous as has been shown. These are summarised in Table 1. Addressing these factors therefore requires understanding their respective degrees of prominence and the causal relationships existing among them. This will aid in effectively focusing efforts to mitigate them. To achieve this, the Decision-Making Trial and Evaluation Laboratory (DEMATEL) technique is adopted in this study to determine the weight of each factor by considering its impact on the other factors. Section 3 provides more information about the technique.

\section{Methodology}

This paper first reviews related literature to identify the root causes of poor medical equipment availability in developing countries as well as current approaches aimed at addressing them. The factors identified from the literature were validated by senior health care workers selected from secondary and tertiary hospitals in Nigeria. The validation was done to confirm that the findings agreed with what was obtainable on ground. The DEMATEL technique was then used to analyse the identified root causes to evaluate their impacts and causal relationship existing among them. The DEMATEL analysis technique was chosen since it can effectively demonstrate mutual influences, both direct and indirect and is therefore suitable in analysing complex cause and effect problems such as the one encountered in this study. Other multicriteria decision methods such as Analytic Hierarchy Process and Technique for order performance by similarity to ideal performance (TOPSIS) fall short in these respects. Unlike these other techniques, DEMATEL also allows aggregated group decision making which can yield more valid results by including inputs from more than one decision maker in the analysis [51].

The relative total prominence of the root causes addressed by remanufacturing was then expressed as a percentage of the overall total prominence of all the factors to determine the potential impact of medical equipment in addressing the root issue of poor medical equipment availability.

\section{The DEMATEL method}

The DEMATEL is a multi-criteria decision-making technique that was firstly applied in the Science and Human Affairs Programme of the Batelle Memorial Institute to analyse complicated interrelationships [66]. It is an efficient technique for exploring the interrelationships among alternative criteria or factors. Apart from its ability to produce a model of interrelationships, DEMATEL can also measure the impact of each factor on the others and can be used to prioritise factors according to relative impacts or degrees of prominence. It also supports group decision making and can be applied to relatively large number of factors to help decision makers in selecting the best strategic alternatives following three key stages as summarised by Ahmet et al. [3]: 
Table 1 Summary of factors responsible for the poor availability of medical equipment in developing countries

\begin{tabular}{|c|c|c|c|}
\hline $\mathrm{S} / \mathrm{N}$ & Factors & Details & References \\
\hline $\mathrm{F} 1$ & Corruption & $\begin{array}{l}\text { Corruption often takes the form of } \\
\text { embezzlement of funds allocated to } \\
\text { the purchase of medical equipment or } \\
\text { stealing of - equipment; often } \\
\text { possible due to the peculiar nature } \\
\text { of health care industry. }\end{array}$ & [8] \\
\hline $\mathrm{F} 2$ & Attitude/Perception & $\begin{array}{l}\text { Staff may refuse to use medical devices } \\
\text { if they consider them difficult to use } \\
\text { or may incorrectly declare an } \\
\text { equipment damaged. }\end{array}$ & {$[45]$} \\
\hline $\mathrm{F} 3$ & $\begin{array}{l}\text { Lack of funds to access } \\
\text { and/or to fund the purchase } \\
\text { of equipment }\end{array}$ & $\begin{array}{l}\text { Governments in many developing } \\
\text { countries often cannot afford the cost } \\
\text { of state-of-the-art equipment. The } \\
\text { people are also poor and may not be } \\
\text { able to pay for procedures involving } \\
\text { expensive medical equipment. }\end{array}$ & {$[11,30,39,45]$} \\
\hline F4 & $\begin{array}{l}\text { Lack of infrastructure such as } \\
\text { electricity, water supply, } \\
\text { oxygen. }\end{array}$ & $\begin{array}{l}\text { Poor infrastructure such as reliable } \\
\text { electricity, water supply, roads, } \\
\text { oxygen. }\end{array}$ & {$[14,17,45,47]$} \\
\hline F5 & Absence of HTM and HTA & The main problems faced regarding & {$[10,38,43,57,62]$} \\
\hline F6 & Weak or absent regulation. & $\begin{array}{l}\text { medical equipment include lack of or } \\
\text { poor health technology management } \\
\text { policy which results in poor planning } \\
\text { for procurement and sustenance. Lack } \\
\text { of regulation affects the effectiveness, } \\
\text { durability and consequently, } \\
\text { the effective lifetime } \\
\text { of medical equipment. }\end{array}$ & \\
\hline F7 & Lack of skilled workers & $\begin{array}{l}\text { Trained experts for use and maintenance } \\
\text { of medical equipment are usually not } \\
\text { available and training is poor }\end{array}$ & {$[5,31,32,43,55]$} \\
\hline F8 & $\begin{array}{l}\text { Lack of spare parts } \\
\text { and consumables }\end{array}$ & $\begin{array}{l}\text { Damage to the equipment requiring } \\
\text { spare parts cannot be rectified due to } \\
\text { the unavailability of the spare parts in } \\
\text { the local market. }\end{array}$ & {$[5,29,33,43,55]$} \\
\hline F9 & Lack of clear economic model & $\begin{array}{l}\text { Developing countries' hospitals do not } \\
\text { often aim to minimise costs whereas } \\
\text { there is need to always conduct } \\
\text { economic evaluation of medical } \\
\text { devices to demonstrate } \\
\text { their cost effectiveness. }\end{array}$ & {$[26,33,43]$} \\
\hline F10 & $\begin{array}{l}\text { Inappropriateness } \\
\text { of available equipment }\end{array}$ & $\begin{array}{l}\text { Available equipment are often } \\
\text { inappropriate for the needs of the } \\
\text { developing countries. They may be } \\
\text { for treatment of diseases that are not } \\
\text { common in the country or are not } \\
\text { designed to be compatible with } \\
\text { realities on ground }\end{array}$ & {$[18,31,33]$} \\
\hline F11 & $\begin{array}{l}\text { Unreliable or ineffective supply } \\
\text { chain communication }\end{array}$ & $\begin{array}{l}\text { Medical equipment are mostly } \\
\text { manufactured outside of developing } \\
\text { countries necessitating supply chain } \\
\text { frameworks which are sadly } \\
\text { inexistent or ineffective. Biomedical } \\
\text { technologists and engineers are also } \\
\text { not part of the procurement process }\end{array}$ & {$[35,47,69]$} \\
\hline
\end{tabular}


Stage 1. Participants in the study were selected as summarised in Table 2, to evaluate in a pairwise manner, the direct impact of each factor $\mathrm{Fi}$ on $\mathrm{Fj}$. Each respondent was first introduced to the identified factors as well as the pattern for conducting the pairwise comparisons. The impact is assessed using integers ranging from 0 to 4 ; with 0 representing no influence, 1 representing very low influence, 2 representing low influence, 3 representing high influence and 4 representing very high influence. The magnitude of each factor's influence is indicated by the notation: $a_{i j}$ which is the degree of influence that factor $i$ has on factor $\mathrm{j}$ according to the assessment of each respondent.

Given that there are $\mathrm{n}$ factors $\left(F_{1}, F_{2}, \ldots F_{n}\right)$ in the resultant $n \times n$ comparison matrix for each expert, then the terms $i=j=0$ representing the diagonal terms will equal zero since a factor would have no impact on itself. Each respondent thus produces the matrix:

$$
A^{b}=\left[a^{b}{ }_{i j}\right], \text { where } b=1,2, \ldots M \text { refer to individual respondents }
$$

Stage 2: To aggregate the views of the respondents, the average of the direct relation matrix is evaluated as follows:

$$
x_{i j}=\frac{1}{M} \sum_{b=1}^{M} a_{i j}
$$

Stage 3: The average direct matrix $\left[x_{i j}\right]$ is normalised to give $T$, according to the following relation:

$$
T=X \times C
$$

Where $\mathrm{X}=\left[x_{i j}\right]$ and $\mathrm{C}=\min \left[\frac{1}{\max \sum_{i=1}^{n} x_{i j}}, \frac{1}{\max \sum_{j=1}^{n} x_{i j}}\right]$

The elements of the normalised matrix T are in the range 0 to 1 .

Stage 4: Finally, the total relation matrix $U$ is calculated using the following equation:

$$
U=T(I-T)^{-1} \quad \text { Where } I \text { is the identity matrix }
$$

In the matrix $\mathrm{U}, r_{i}$ is the $i^{\text {th }}$ row sum in the matrix $\mathrm{U}$ and signifies the sum of direct and indirect effects emanating from $F_{i}$ to other factors. Similarly, $c_{j}$ is the $j^{\text {th }}$ column sum in the same matrix and represents the sum of direct and indirect effects impacting on factor $F_{j}$ from other factors. Hence,

$$
\begin{aligned}
& \mathrm{R}=\left[r_{i}\right]_{n x 1}=\left[\sum_{j=1}^{n} u_{i j}\right]_{n x 1} \\
& \mathrm{C}=\left[c_{j}\right]_{1 x n}=\left[\sum_{j=1}^{n} u_{i j}\right]_{1 x n}
\end{aligned}
$$

Table 2 Characteristics of respondents for the pairwise comparison

\begin{tabular}{llll}
\hline Respondent & Type of Organisation & Profession & $\begin{array}{l}\text { Number of years } \\
\text { of experience }\end{array}$ \\
\hline 1 & State teaching hospital & Biomedical Engineer & 9 \\
2 & Federal teaching hospital & Senior Radiographer & 8 \\
3 & State university/teaching hospital & Biomedical Engineering Lecturer & 10 \\
4 & Mission hospital & Medical Doctor & 7 \\
5 & State Teaching Hospital & Biomedical Engineer & 9 \\
6 & Federal Teaching hospital & Biomedical Engineer & 22 \\
7 & Private hospital & Medical Doctor & 7 \\
8 & Independent medical equipment & Biomedical & 23 \\
& designer and repairer & Engineering Technologist & \\
\hline
\end{tabular}




\section{Characteristics of study participants}

The participants in this study were selected based on their experience in their respective positions and good understanding of medical equipment related issues in their organisations. They come from private, secondary and tertiary hospitals where medical equipment need is extensive. One of the participants is also, actively involved in design and maintenance of medical equipment for local use. Hence, the participants' views are valid and capable of representing the reality regarding factors affecting medical equipment availability. In this study, inputs from 8 participants were used. Compared to Shao and Mier [50] which only included three participants and et al. [3] which used inputs from only 5 participants, the number of participants in this study can be assumed to be substantial.

\section{Results}

Given that the vectors $\left[r_{i}\right]_{n \times 1}$ and $\left[c_{j}\right]_{1 \times n}$ in the matrix $\mathrm{U}$ represent the sum of the columns and sum of the rows of the total direct relation matrix respectively, then $r_{i}$ represent the direct and indirect impacts of factor $F_{i}$ on other factors. Similarly, $c_{j}$ represents the direct and indirect impacts of other factors on factor $F_{j}$. The sum $(R+C)$ otherwise referred to as the Prominence expresses the total effects caused and received by a factor. On the other hand, the difference $(R-C)$ called the Relation represents its net influence on the others. If the value $(\mathrm{R}+\mathrm{C})>$ 0 , then the factor is a driving factor, otherwise the factor would be a driven factor if $(\mathrm{R}-\mathrm{C})<0$. A threshold value is computed from the total relation matrix $U$ which represents the minimum significant influence to be considered individually. The threshold may be calculated following Shao and Mier's technique by summing the mean of the total relation matrix and its standard deviation as follows:

$$
\operatorname{Mean}(U)+\sigma(U)
$$

Stronger causal relationships may also be obtained by instead, adding two standard deviations of the total relation matrix; that is:

$$
\operatorname{Mean}(U)+2 \sigma(U) \text {. }
$$

Table 3 summarises the values that are up to these thresholds. Values marked with asterisk are those exceeding the second threshold obtained by adding two times the standard deviations of the total relation matrix to its mean.

\section{Degrees of prominence of factors}

The degrees of prominence and characteristics of each factor are as summarised in Table 4. It is based on the $(\mathrm{R}+\mathrm{C})$ values and is as follows:

$$
F 1>F 9>F 3>F 5>F 6>F 8>F 7>F 2>F 4>F 10>F 11 .
$$

Thus, corruption (F1) is the most prominent reason for shortage of medical equipment while unreliable supply chain communication (F11) is the least. In addition, corruption (F1), lack of clear economic model (F9), lack of funds (F3), absence of HTA and HTM policies (F5), Weak or 


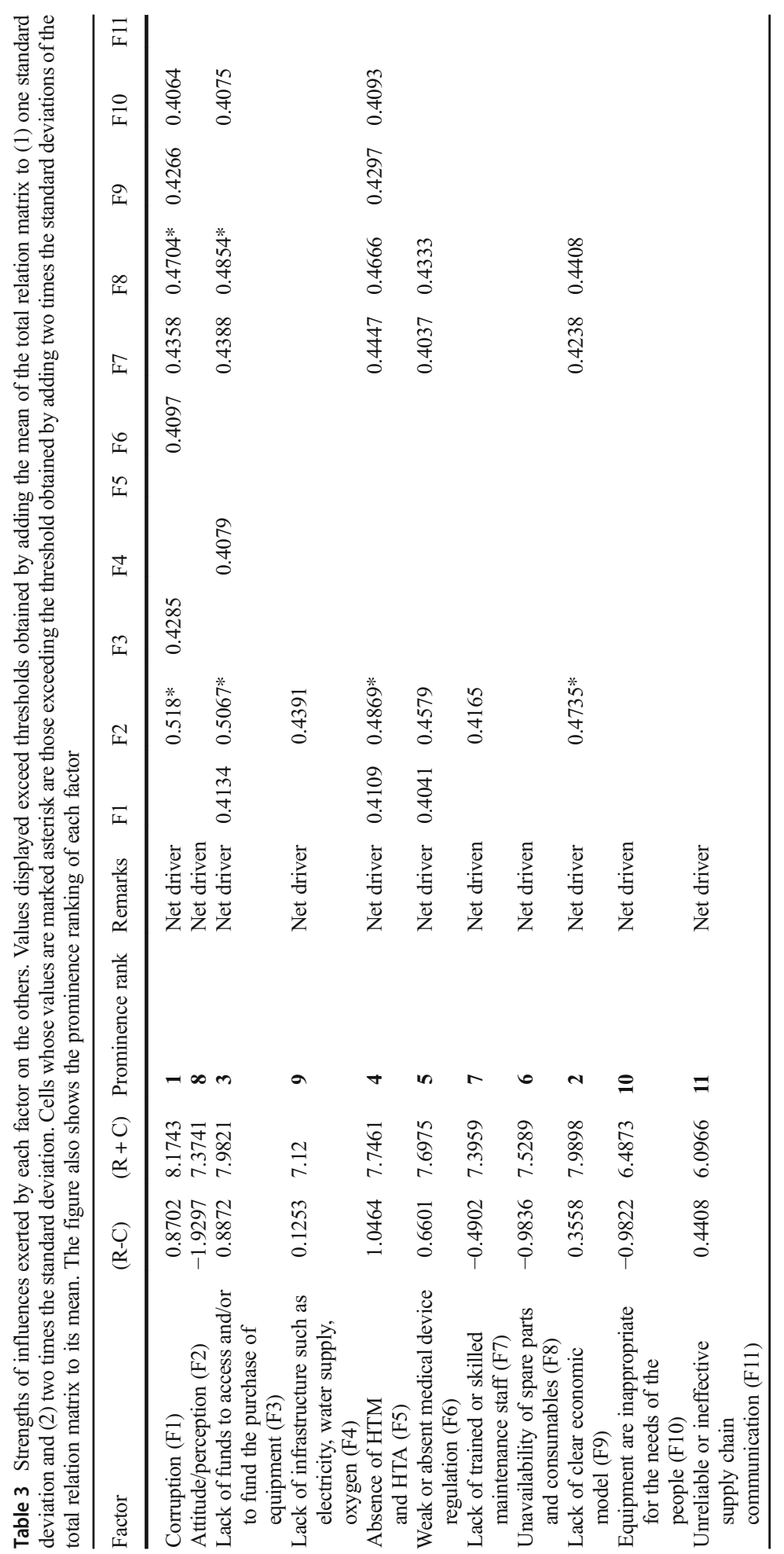


Table 4 Potential contribution of remanufacturing in increasing availability of medical equipment remanufacturing

\begin{tabular}{|c|c|c|c|}
\hline Factor & $\begin{array}{l}\text { Total } \\
\text { prominence } \\
(R+C)\end{array}$ & $\begin{array}{l}\text { Potential to be } \\
\text { addressed } \\
\text { by remanufacturing }\end{array}$ & References \\
\hline Corruption & 8.1743 & & \\
\hline Attitude/perception & 7.3741 & & \\
\hline $\begin{array}{l}\text { Lack of funds to access } \\
\text { and/or to fund the purchase } \\
\text { of equipment }\end{array}$ & 7.9821 & $\sqrt{ }$ & $\begin{array}{l}\text { Remanufacturing can provide low } \\
\text { cost alternatives }[9,21,22,25,41]\end{array}$ \\
\hline $\begin{array}{l}\text { Lack of infrastructure } \\
\text { such as electricity, water } \\
\text { supply, oxygen }\end{array}$ & 7.12 & & \\
\hline Absence of HTM and HTA & 7.7461 & & \\
\hline $\begin{array}{l}\text { Weak or absent medical } \\
\text { device regulation }\end{array}$ & 7.6975 & & \\
\hline $\begin{array}{l}\text { Lack of trained or skilled } \\
\text { maintenance staff }\end{array}$ & 7.3959 & $\sqrt{ }$ & $\begin{array}{l}\text { Remanufacturing develops } \\
\text { skills }[21,22,44]\end{array}$ \\
\hline $\begin{array}{l}\text { Unavailability of spare parts } \\
\text { and consumables }\end{array}$ & 7.5289 & $\sqrt{ }$ & $\begin{array}{l}\text { Spare parts provision which enables } \\
\text { prolonged use of products and } \\
\text { components even after their } \\
\text { production has ceased }[21,49]\end{array}$ \\
\hline Lack of clear economic model & 7.9898 & & \\
\hline $\begin{array}{l}\text { Equipment are inappropriate for } \\
\text { the needs of the people }\end{array}$ & 6.4873 & $\sqrt{ }$ & $\begin{array}{l}\text { By engaging local workers, the issue } \\
\text { of needs communication along }\end{array}$ \\
\hline $\begin{array}{l}\text { Unreliable or ineffective supply } \\
\text { chain communication }\end{array}$ & 6.0966 & $\sqrt{ }$ & $\begin{array}{l}\text { supply chains will be } \\
\text { addressed }[53,54]\end{array}$ \\
\hline
\end{tabular}

absent regulation (F6), lack of infrastructure (F4) and unreliable or ineffective supply chain and communication involving recipients (F11) are net drivers. On the other hand, the driven factors include unavailability of spare parts and consumables (F8), lack of trained or skilled maintenance staff (F7), workers' attitudes and perception (F2) and equipment inappropriate for the needs (F10) are net influenced factors responsible for the poor availability of medical equipment.

Table 3 also shows that corruption is driven by lack of funds (F3), absence of HTA and HTM (F5) and weak or absent medical device regulation (F6). Similarly, workers' perception and attitude (F2) is driven by corruption (F1), lack of funds (F3), lack of infrastructure (F4), absence of HTA and HTM (F5), weak or absent medical device regulation (F6), lack of trained or skilled maintenance staff (F7) and lack of clear economic model (F9). Corruption (F1) is the main cause of lack of funds (F3) which is at the same time, responsible for lack of infrastructure (F4). Corruption (F1) is also the most important factor responsible for the weak or absent medical device regulation (F6). Lack of trained maintenance staff (F7) and unavailability of spares and consumables (F8) are both driven by corruption (F1), lack of funds (F3), absence of HTA and HTM (F5), weak or absent medical device regulation (F6) as well as lack of clear economic models (F9). However, lack of clear economic models (F9) is caused by corruption (F1) and absence of HTA and HTM (F5). Finally, equipment are inappropriate for healthcare needs (F10) because of corruption (F1), lack of funds (F3) and absence of HTA and HTM (F5).

\section{Potential impact of remanufacturing as a sustainable solution to the problem}

Remanufacturing can contribute towards addressing some of the factors responsible for the poor availability of medical equipment. Specifically, remanufacturing can provide 
affordable quality medical equipment since in general, remanufactured products are sold at much lower price than equivalent new ones $[22,25,52]$. The price of remanufactured products average at $60 \%$ of those of equivalent new products [20, 41]. This lower price achievable since only about $15 \%$ of the energy required to manufacture equivalent new products is utilised in remanufacturing [9, 22]. Moreover, remanufacturing has the potential to create an industrial base for developing countries [44] through associated workforce training, new equipment procurement and technology transfer. This is because remanufacturing is labour intensive [22, 44] and currently requires less technological sophistication than conventional manufacturing. Thus, it can potentially promote commercial activity in the medical device sector and contribute to skills development in medical equipment technology. Thus, medical equipment remanufacturing can help to develop skilled manpower needed for the maintenance of medical equipment.

Another key feature of remanufacturing is its incorporation with product sales service (PSS) which involves a greater focus on the product's functionality rather than mere products $[15,63]$. Through this strategy, remanufacturing can provide increased access to spare parts [49]. This is achievable since both whole products and sub-assembles can be remanufactured [22]. Medical equipment remanufacturing therefore, also has the potential to increase access to functional medical equipment spare parts and can help address the challenge of unavailability of spare parts.

The success of remanufacturing depends largely on communication among supply chain players including users $[40,53]$. Medical equipment remanufacturing can help bridge such communication gap among users through its emphasis on PSS which is aimed at optimising the utility that products offer their users. Further, by implementing remanufacturing, imported medical equipment can be adapted to developing country needs and specifications in a manner that will ensure that the product would serve appropriately.

The potential contribution of medical equipment remanufacturing in addressing the poor availability of medical equipment may be estimated as a percentage of the overall total prominence, as follows:

$$
100 \times \frac{\sum_{i=1}^{m} p_{i}}{\sum_{j=1}^{n} p_{j}}=\frac{\sum_{i=1}^{k} r_{i}+c_{i}}{\sum_{j}^{l} r_{i}+c_{i}},
$$

$k=5=$ number of factors potentially addressed by remanufacturing as shown in Table 4

$l=11=$ total number of factors

$P_{i}=$ total prominence of the 5 factors potentially addressed by remanufacturing(Table 4)

$P_{j}=$ total prominence of all 11 factors affecting medical equipment availability

Thus, the potential contribution of medical equipment remanufacturing in addressing medical equipment availability is approximately $43.5 \%$.

\section{Remanufacturing as a potential sustainable solution for increasing medical equipment availability in developing countries}

According to Pearce [42], the following types of customers are likely to be interested in remanufactured products: 
- Those that need to retain a specific product for their processes.

- Users that want to avoid the rigour of the recertification or re-approval process preceding product purchasing.

- Those that make relatively less use of new equipment and are price sensitive.

- Those that would like to continue the use of products whose OEMs no longer produce

- Customers that may only want to extend the service life of their used equipment.

- Customers that are environmentally conscious.

The shortage of basic life-saving medical equipment in developing countries suggests that health care institutions would wish to retain their medical equipment for long time, even after OEMs have discontinued their production. Moreover, developing countries are not accustomed to using new and state of the equipment [38] and are price sensitive due to lack of funds. It therefore appears highly likely that health care systems in developing countries will benefit from medical equipment remanufacturing.

\section{Recommendations}

The results of this study indicate that the absence of HTM and HTA contribute to the unavailability of skilled maintenance staff, unavailability of spare parts and consumables, lack of economic model as well as acquisition of equipment that are inappropriate for health care needs. HTA and HTM play key roles in healthcare; yet they are almost weak or absent in many developing countries. While HTA ensures that technologies are appropriate towards addressing prevailing healthcare challenges, HTM guarantees successful utilisation of medical equipment. Implementing HTA and HTM thus, includes gathering reliable information about proposed new equipment; planning and selecting technologies based on prevailing needs, making resources available to ensure the sustainability of equipment, purchasing the right models of equipment and installing them correctly as well as making plans for decommissioning, disposal and replacement of unsafe or obsolete equipment. Thus, HTA and HTM policies are to be motivated by the type of health care an organisation intends to provide and thus; contributes to the achievement of standardisation, improved maintenance practice as well as resource optimisation [28]. Such standardisation facilitates the development of maintenance capability and improved access to spare parts. HTM policies ensure that budgetary provision is made for the maintenance of technologies along their life cycles and thus, incorporates some economic consideration regarding sourcing of funds. Economic models may include limiting the length of hospital stay and ensuring that expensive procedures and techniques are reserved as last options. Weak or absent regulation also contributes to the lack of skilled maintenance staff as well as lack of spare parts and consumables. According to one of the study participants,

"Medical equipment come into the country from many sources without passing through standard pre-entry evaluation. The safety, effectiveness and durability of equipment are thus, not guaranteed and so, they break down too frequently."

When equipment, especially the second-hand ones are imported without the necessary regulatory coordination and control, the risk of not being able to source spare parts emanates. This is mostly the case when the manufacturers have discontinued the production of spare parts [24]. This study finds that corruption contributes to the inefficiency of medical equipment regulation. One of the respondents to the study observed that policies 
and frameworks are usually available but not implemented since those responsible are often easily compromised. Governments and relevant organisations may take decisive action against corrupt acts which hinder regulatory dispensation as well as formulate and implement robust HTA and HTM policies.

\section{Conclusions}

The analysis performed in this research shows that corruption is the most important factor, followed by lack of clear economic model and then lack of funds. Current approaches towards addressing the availability issue has proven to be unsustainable. This paper however, demonstrates that remanufacturing is potentially capable of contributing towards solving five of the root causes of the problem; accounting for $43.5 \%$ of the overall total prominence of the identified root causes. In addition to remanufacturing, other recommendations including taking decisive action against corruption in all its forms, formulation and implementation of robust HTA and HTM as well as regulatory policies are suggested to help address the problem.

This study has some obvious limitations in its estimation of the potential impact of medical equipment remanufacturing. First, it relies on the experience of just 8 participants. It has also not accounted for the vagueness in human judgement. Other potential areas of future work in the area include developing decision support tools for medical equipment for remanufacturing and conducting case studies to assess the feasibility of remanufacturing individual medical equipment.

\section{Appendix: Pairwise comparison matrices}

$$
\begin{aligned}
& \mathrm{A}^{1}=\left[\begin{array}{lllllllllll}
0 & 4 & 4 & 3 & 4 & 2 & 3 & 3 & 3 & 3 & 3 \\
4 & 0 & 1 & 3 & 1 & 2 & 2 & 1 & 1 & 0 & 1 \\
4 & 4 & 0 & 3 & 3 & 1 & 2 & 3 & 0 & 3 & 2 \\
4 & 4 & 4 & 0 & 2 & 1 & 1 & 3 & 2 & 1 & 0 \\
4 & 4 & 4 & 3 & 0 & 3 & 3 & 1 & 1 & 4 & 3 \\
4 & 4 & 2 & 4 & 3 & 0 & 1 & 3 & 1 & 4 & 2 \\
3 & 4 & 4 & 4 & 1 & 2 & 0 & 4 & 1 & 2 & 1 \\
3 & 4 & 4 & 4 & 1 & 1 & 3 & 0 & 3 & 1 & 1 \\
2 & 2 & 3 & 3 & 1 & 1 & 2 & 3 & 0 & 3 & 2 \\
2 & 1 & 2 & 4 & 1 & 4 & 1 & 3 & 3 & 0 & 1 \\
2 & 1 & 4 & 3 & 1 & 4 & 3 & 4 & 3 & 4 & 0
\end{array}\right] \quad \mathrm{A}^{2}=\left[\begin{array}{lllllllllll}
0 & 4 & 4 & 4 & 3 & 4 & 4 & 4 & 3 & 4 & 3 \\
0 & 0 & 1 & 1 & 0 & 3 & 3 & 0 & 1 & 0 & 2 \\
0 & 0 & 0 & 4 & 2 & 2 & 2 & 4 & 1 & 2 & 0 \\
0 & 3 & 0 & 0 & 0 & 3 & 0 & 0 & 1 & 0 & 1 \\
4 & 3 & 2 & 2 & 0 & 4 & 2 & 0 & 4 & 0 & 1 \\
4 & 4 & 2 & 2 & 4 & 0 & 3 & 4 & 3 & 0 & 1 \\
0 & 3 & 0 & 2 & 0 & 0 & 0 & 0 & 3 & 0 & 1 \\
0 & 3 & 0 & 0 & 0 & 0 & 0 & 0 & 3 & 0 & 2 \\
0 & 4 & 3 & 2 & 3 & 4 & 4 & 3 & 0 & 0 & 2 \\
1 & 3 & 0 & 0 & 0 & 0 & 0 & 0 & 0 & 0 & 1 \\
0 & 1 & 0 & 0 & 0 & 0 & 0 & 0 & 1 & 0 & 0
\end{array}\right] \\
& \mathrm{A}^{3}=\left[\begin{array}{lllllllllll}
0 & 3 & 3 & 3 & 2 & 3 & 2 & 3 & 3 & 2 & 3 \\
3 & 0 & 2 & 2 & 2 & 3 & 3 & 2 & 3 & 3 & 2 \\
3 & 4 & 0 & 2 & 2 & 2 & 2 & 3 & 3 & 2 & 2 \\
3 & 3 & 0 & 0 & 2 & 3 & 2 & 2 & 3 & 2 & 2 \\
0 & 3 & 0 & 1 & 0 & 3 & 2 & 3 & 2 & 3 & 2 \\
3 & 2 & 2 & 0 & 0 & 0 & 3 & 2 & 3 & 3 & 3 \\
3 & 2 & 0 & 0 & 0 & 0 & 0 & 3 & 3 & 2 & 2 \\
0 & 3 & 1 & 0 & 0 & 0 & 0 & 0 & 3 & 3 & 2 \\
0 & 3 & 3 & 3 & 3 & 0 & 3 & 3 & 0 & 4 & 3 \\
0 & 3 & 0 & 0 & 0 & 0 & 0 & 0 & 0 & 0 & 3 \\
0 & 2 & 0 & 0 & 0 & 0 & 0 & 3 & 3 & 0 & 0
\end{array}\right] \quad \mathrm{A}^{4}=\left[\begin{array}{lllllllllll}
0 & 3 & 2 & 2 & 4 & 4 & 3 & 0 & 3 & 1 & 1 \\
3 & 0 & 2 & 3 & 2 & 4 & 1 & 0 & 1 & 1 & 1 \\
3 & 3 & 0 & 1 & 3 & 3 & 1 & 3 & 3 & 1 & 1 \\
1 & 2 & 2 & 0 & 1 & 3 & 0 & 1 & 3 & 3 & 0 \\
2 & 3 & 3 & 3 & 0 & 2 & 3 & 3 & 3 & 2 & 0 \\
4 & 2 & 2 & 1 & 4 & 0 & 1 & 1 & 3 & 3 & 3 \\
3 & 3 & 3 & 1 & 1 & 3 & 0 & 2 & 3 & 3 & 0 \\
1 & 2 & 2 & 2 & 3 & 1 & 2 & 0 & 2 & 2 & 3 \\
3 & 3 & 1 & 0 & 1 & 2 & 3 & 3 & 0 & 0 & 1 \\
1 & 1 & 0 & 1 & 0 & 1 & 0 & 0 & 3 & 0 & 0 \\
2 & 1 & 0 & 0 & 3 & 2 & 0 & 3 & 2 & 3 & 0
\end{array}\right]
\end{aligned}
$$




$$
\mathrm{A}^{5}=\left[\begin{array}{lllllllllll}
0 & 4 & 3 & 0 & 3 & 3 & 0 & 2 & 2 & 3 & 0 \\
1 & 0 & 3 & 3 & 4 & 3 & 2 & 2 & 1 & 0 & 0 \\
3 & 1 & 0 & 4 & 3 & 3 & 3 & 4 & 0 & 3 & 1 \\
4 & 3 & 0 & 0 & 3 & 3 & 3 & 3 & 0 & 3 & 3 \\
3 & 1 & 3 & 3 & 0 & 0 & 3 & 3 & 4 & 3 & 0 \\
3 & 1 & 3 & 3 & 4 & 0 & 3 & 3 & 3 & 2 & 2 \\
4 & 3 & 2 & 1 & 0 & 0 & 0 & 3 & 0 & 2 & 0 \\
3 & 2 & 3 & 0 & 0 & 0 & 3 & 0 & 0 & 4 & 0 \\
2 & 2 & 3 & 1 & 3 & 3 & 2 & 3 & 0 & 3 & 1 \\
3 & 4 & 3 & 4 & 0 & 1 & 2 & 4 & 3 & 0 & 0 \\
1 & 1 & 0 & 4 & 0 & 3 & 0 & 4 & 1 & 4 & 0
\end{array}\right] \mathrm{A}^{6}=\left[\begin{array}{llllllllllll}
0 & 3 & 4 & 4 & 3 & 3 & 3 & 2 & 2 & 4 & 3 \\
3 & 0 & 3 & 3 & 4 & 4 & 3 & 3 & 2 & 3 & 2 \\
4 & 3 & 0 & 3 & 2 & 3 & 4 & 4 & 2 & 3 & 1 \\
4 & 4 & 4 & 0 & 1 & 3 & 4 & 3 & 1 & 3 & 2 \\
3 & 1 & 2 & 2 & 0 & 2 & 3 & 2 & 1 & 1 & 2 \\
3 & 2 & 4 & 4 & 2 & 0 & 2 & 3 & 1 & 2 & 2 \\
3 & 4 & 2 & 2 & 3 & 3 & 0 & 3 & 2 & 2 & 1 \\
3 & 2 & 3 & 3 & 1 & 2 & 3 & 0 & 2 & 2 & 2 \\
2 & 1 & 3 & 3 & 2 & 3 & 1 & 1 & 0 & 2 & 1 \\
3 & 1 & 1 & 1 & 1 & 1 & 1 & 1 & 1 & 0 & 2 \\
2 & 3 & 4 & 4 & 4 & 3 & 2 & 3 & 3 & 3 & 0
\end{array}\right]
$$

Open Access This article is licensed under a Creative Commons Attribution 4.0 International License, which permits use, sharing, adaptation, distribution and reproduction in any medium or format, as long as you give appropriate credit to the original author(s) and the source, provide a link to the Creative Commons licence, and indicate if changes were made. The images or other third party material in this article are included in the article's Creative Commons licence, unless indicated otherwise in a credit line to the material. If material is not included in the article's Creative Commons licence and your intended use is not permitted by statutory regulation or exceeds the permitted use, you will need to obtain permission directly from the copyright holder. To view a copy of this licence, visit http://creativecommons.org/licenses/by/4.0/.

\section{References}

1. Ademe BW, Tebeje B, Molla A (2016) Availability and utilization of medical devices in Jimma zone hospitals, Southwest Ethiopia: a case study. BMC Health Serv Res 16:287. https://doi.org/10.1186/s12913016-1523-2

2. Adjabu N, Bradley B, Gentles B, Mirzazadeh C (2014) A study of medical equipment donations from Canada to developing countries: Progress and challenges. Appropr Healthc Technol Low Resour Settings: $1-4$

3. Ahmed S, Ahmed S, Shumon MRH, Quader MA, Cho HM, Mahmud MI (2016) Prioritizing strategies for sustainable end-of-life vehicle management using combinatorial multi-criteria decision making method. Int J Fuzzy Syst 18:448-462. https://doi.org/10.1007/s40815-015-0061-0

4. Allan Kaplan W, Sarah Ritz L, Vitello M (2011) Local production of medical technologies and its effect on access in low and middle income countries: a systematic review of the literature. South Med Rev 42:51-61. https://doi.org/10.5655/smr.v4i2.1002

5. Ankomah J, Stewart BT, Oppong-Nketia V, Koranteng A, Gyedu A, Quansah R, Donkor P, Abantanga F, Mock C (2015) Strategic assessment of the availability of pediatric trauma care equipment, technology and supplies in Ghana. J Pediatr Surg 50:1922-1927. https://doi.org/10.1016/j.jpedsurg.2015.03.047

6. Bamber P (2013) Costa Rica in the medical devices global value chain. Durham

7. Borrás C, Calil SJ, David Y, Pallikarakis NE, Secca MF (2014) IFMBE proceedings 45 - IUPESM-HTTG workshop on radiological equipment maintenance issues. IFMBE Proc 45. doi: https://doi.org/10.1007/9783-319-11128-5 230 
8. Bouchard M, Kohler JC, Orbinski J, Howard A (2012) Corruption in the health care sector: a barrier to access of orthopaedic care and medical devices in Uganda. BMC Int Health Hum Rights 12:1-9. https://doi. org/10.1186/1472-698X-12-5

9. Brent AC, Steinhilper R (2005) Opportunities for remanufactured electronic products from developing countries: hypotheses to characterise the perspectives of a global remanufacturing industry. SAIEE Africa Res J 96:196-201. https://doi.org/10.1109/AFRICON.2004.1406815

10. Coe GA, Banta D (1992) Health care technology transfer in Latin America and the Caribbean. Int J Technol Assess Health Care 8:255-267

11. Daher H, Flessa S (2010) Microfinance as a tool for financing medical devices in Syria An assessment of needs and a call for further research. J Public Health (Bangkok) 18:189-197. https://doi.org/10.1007 /s10389-009-0290-5

12. Eltringham R, Neighbour R (2012) The design of medical equipment for low income countries: dual standards or common sense. In: 7th international conference on appropriate healthcare Technologies for Developing Countries. Institution of Engineering and Technology, pp 31-31

13. Eltringham R, Neighbour R (2014) The reality of designing appropriate 'low cost' medical products for developing countries and their unintended consequences. In: appropriate healthcare Technologies for low Resource Settings (AHT 2014). Institution of Engineering and Technology, pp 32-32

14. Enright A (2013) Review article: safety aspects of anesthesia in under-resourced locations. Can J Anesth

15. Eze S, Ijomah W, Wong TC (2019) Accessing medical equipment in developing countries through remanufacturing. J Remanufacturing 9:1-27. https://doi.org/10.1007/s13243-018-0065-7

16. Fathima S, Rohloff P, King NE, Hall-Clifford R, Stroux L, Clifford GD (2014) A low-cost perinatal monitoring system for use in rural Guatemala. In: appropriate healthcare Technologies for low Resource Settings (AHT 2014). Institution of Engineering and Technology, pp 17-17

17. Gatrad AR, Gatrad S, Gatrad A (2007) Equipment donation to developing countries. Anaesthesia 62:90-95. https://doi.org/10.1111/j.1365-2044.2007.05309.x

18. Gauthier AK, Cruz G, Medina L, Duke S (2013) Design factors for medical device functionality in developing countries. IIE Annu Conf Proc 2227-2236

19. Gehin A, Zwolinski P, Brissaud D (2008) A tool to implement sustainable end-of-life strategies in the product development phase. J Clean Prod 16:566-576. https://doi.org/10.1016/j.jclepro.2007.02.012

20. Giutini R, Gaudette K (2003) Remanufacturing: the next great opportunity for boosting US productivity. Bus Horiz 46:41-48. https://doi.org/10.1016/S0007-6813(03)00087-9

21. Goodall P, Rosamond E, Harding J (2014) A review of the state of the art in tools and techniques used to evaluate remanufacturing feasibility. J Clean Prod 81:1-15. https://doi.org/10.1016/j.jclepro.2014.06.014

22. Gray C, Charter M (2007) Remanufacturing and product design - designing for the 7th generation. Surrey

23. Hazen BT, Mollenkopf DA, Wang Y (2016) Remanufacturing for the circular economy: an examination of consumer switching behavior. Bus Strateg Environ 26:451-464. https://doi.org/10.1002/bse.1929

24. Hutubessy RCW, Hanvoravongchai P, Edejer TT-T (2002) Diffusion and utilization of magnetic resonance imaging in Asia. Int J Technol Assess Health Care 18:690-704

25. Ijomah WL, Childe S, Mcmahon C (2004) Remanufacturing: a key strategy for sustainable development. In: 3rd international conference on design and manufacture for sustainable development. Loughborough

26. Judd TM, Issakov A (2008) GAME HTM project in Kosovo and future plans elsewhere. In: 5th IET international seminar on appropriate healthcare Technologies for Developing Countries (AHT 2008). IEE, pp 16-16

27. De la Fuente MV, Ros L, Cardos M (2008) Integrating forward and reverse supply chains: application to a metal-mechanic company. Int J Prod Econ 111:782-792. https://doi.org/10.1016/j.ijpe.2007.03.019

28. Lenel A. et al (2005) Guide 1: how to organize a system of healthcare technology management. 'How to Manag Ser Healthc Technol 167

29. Mahal A, Varshney A, Taman S (2018) Diffusion of diagnostic medical devices and policy implications for India. Int J Technol Assess Health Care 22:184-190. https://doi.org/10.1017/S0266462306051002

30. Malkin R a (2007) Barriers for medical devices for the developing world. Expert Rev Med Devices doi: https://doi.org/10.1586/17434440.4.6.759

31. Malkin R, Keane A (2010) Evidence-based approach to the maintenance of laboratory and medical equipment in resource-poor settings. Med Biol Eng Comput 48:721-726

32. Malkin RA (2007) Barriers for medical devices for the developing world. Expert Rev Med Devices 4:759763. https://doi.org/10.1586/17434440.4.6.759

33. Malkin RA (2007) Design of health care technologies for the developing world. Annu Rev Biomed Eng 9: 567-587. https://doi.org/10.1146/annurev.bioeng.9.060906.151913

34. Mateosian R (2001) Making it work: a tool kit for medical equipment donations to low resource settings

35. McGuire H, Weigl BH (2014) Medical devices and diagnostics for cardiovascular diseases in low-resource settings. J Cardiovasc Transl Res 7:737-748. https://doi.org/10.1007/s12265-014-9591-3 
36. Nimunkar AJ, Baran J, Van Sickle D, Pagidimarry NK, Webster JG (2009) Medical devices for developing countries: design constraints and approaches. In: 2009 annual international conference of the IEEE engineering in medicine and biology society. IEEE, pp 7048-7051

37. Nimunkar AJ, Baran J, Sickle D Van, Webster JG (2008) Low-cost Medical Devices for Developing Countries. None 53706:None

38. Nkuma-Udah KI, Agoha EEC, Ejeta K, Ndubuka GI (2015) biomedical engineering in Nigeria: a developmental overview. In: IFMBE Proceedings. pp 1643-1648

39. O'Hara NN (2015) Is safe surgery possible when resources are scarce? BMJ Qual Saf. https://doi. org/10.1136/bmjqs-2015-004377

40. Östlin J, Sundin E, Björkman M (2008) Importance of closed-loop supply chain relationships for product remanufacturing. Int J Prod Econ 115:336-348. https://doi.org/10.1016/j.ijpe.2008.02.020

41. Parkinson HJ, Thompson G (2003) Analysis and taxonomy of remanufacturing industry practice. Proc Inst Mech Eng Part E J Process Mech Eng 217:243-256. https://doi.org/10.1243/095440803322328890

42. Pearce John A (2009) The profit-making allure of product reconstruction - MIT SMR store. MIT Sloan Manag Rev 50:59-63

43. Perry L, Malkin R (2011) Effectiveness of medical equipment donations to improve health systems: how much medical equipment is broken in the developing world? Med Biol Eng Comput 49:719-722. https://doi.org/10.1007/s11517-011-0786-3

44. Lund RT (1984) Remanufacturing : the experience of the United States and implications for developing countries (English) | the World Bank. World Bank, Washington DC

45. Rosen MA, Sampson JB, Jackson EV, Koka R, Chima AM, Ogbuagu OU, Marx MK, Koroma M, Lee BH (2014) Failure mode and effects analysis of the universal anaesthesia machine in two tertiary care hospitals in Sierra Leone. Br J Anaesth. https://doi.org/10.1093/bja/aeu096

46. Saavedra YMBB, Barquet APBB, Rozenfeld H, Forcellini FA, Ometto AR (2013) Remanufacturing in Brazil: case studies on the automotive sector. J Clean Prod 53:267-276. https://doi.org/10.1016/j. jclepro.2013.03.038

47. Sandhu JS, Bhandari A, Ibrahim M, Balakrishnan P (2005) Appropriate Design of Medical Technologies for emerging regions: the case of Aurolab. In: Engineering/Technology Management

48. Santos IC, Gazelle GS, Rocha LA, Tavares JMR (2012) Medical device specificities: opportunities for a dedicated product development methodology. Expert Rev Med Devices 9:299-311. https://doi.org/10.1586 /erd.12.3

49. Seitz MA (2007) A critical assessment of motives for product recovery: the case of engine remanufacturing. J Clean Prod 15:1147-1157. https://doi.org/10.1016/j.jclepro.2006.05.029

50. Shao J, Taisch M, Ortega-Mier M (2016) A grey-DEcision-MAking trial and evaluation laboratory (DEMATEL) analysis on the barriers between environmentally friendly products and consumers: practitioners' viewpoints on the European automobile industry. J Clean Prod 112:3185-3194. https://doi. org/10.1016/j.jclepro.2015.10.113

51. Si S, You X, Liu H, Zhang P (2018) DEMATEL technique : a systematic review of the state-of-the-art literature on methodologies and applications. Math Probl Eng 2018:33. Doi: https://doi.org/10.1155/2018 13696457

52. Steinhilper R (1998) Remanufacturing: the ultimate form of recycling. 1-24

53. Sundin E, Dunbäck O (2013) Reverse logistics challenges in remanufacturing of automotive mechatronic devices. J Remanufacturing 3:1-8. https://doi.org/10.1186/2210-4690-3-2

54. Sundin E, Ostlin J, Ronnback AO, Lindahl M, Sandstrom GO (2008) Remanufacturing of products used in product service system offerings. In: Mitsuishi, M and Ueda, K and Kimura, F (ed) Manufacturing Systems and Technologies For The New Frontier. P 537+

55. Tanyanyiwa DM (2010) Cost challenges for laboratory medicine automation in Africa. Pan Afr Med J 6:22

56. Unger S, Landis A (2016) Assessing the environmental, human health, and economic impacts of reprocessed medical devices in a Phoenix hospital's supply chain. J Clean Prod 112:1995-2003. https://doi.org/10.1016/j.jclepro.2015.07.144

57. Velazquez A (2002) Health care technology management challenges in Mexico: increase clinical engineering services and develop telemedicine nationwide. In: proceedings of the second joint 24th annual conference and the annual fall meeting of the Biomedical Engineering Society] [engineering in medicine and biology. IEEE, p 1914

58. Venturini S (2018) Park KB. Evaluating the Effectiveness and the Impact of Donated Neurosurgical Equipment on Neurosurgical Units in Low- and Middle-Income Countries, The World Federation of Neurosurgical Societies Experience. https://doi.org/10.1016/j.wneu.2017.09.117

59. WHO (2000) Guidelines for health care equipment donations. World health organisation

60. WHO (2010) Barriers to Innovation in the Field of Medical Devices: Background Paper 06. http://apps.who. int/medicinedocs/en/d/Js17701en/. 
61. WHO (2011) Medical device donations: considerations for solicitation and provision

62. WHO (2017) Global Atlas of Medical Devices: WHO medical devices technical series

63. Widera H, Seliger G (2015) Methodology for exploiting potentials of remanufacturing by reducing complexity for original equipment manufacturers. CIRP Ann - Manuf Technol 64:463-466. https://doi. org/10.1016/j.cirp.2015.04.111

64. Winifred I (2002) A model-based definition of the generic remanufacturing business process. University of Plymouth

65. World Health Organisation (2016) Towards improving access to medical devices through local production Phase II

66. Wu HH, Tsai YN (2011) A DEMATEL method to evaluate the causal relations among the criteria in auto spare parts industry. Appl Math Comput 218:2334-2342. https://doi.org/10.1016/j.amc.2011.07.055

67. Zaidi MK (1985) Iomp - Used Equipment Donations Program

68. Zarocostas J (2010) WHO calls for better access to medical devices in poor nations - ProQuest. In: Br. Med. J. https://search.proquest.com/docview/1909599990?pq-origsite=gscholar. Accessed 14 Sep 2017

69. Zomboko FE, Tripathi SK, Kamuzora FK (2012) Challenges in procurement and use of donated medical equipment: study of a selected referral hospital in Tanzania. Int ref res J $\mathbf{a}$ www.researchersworld.com $\mathbf{\square} 41$

70. Zubizarreta EH, Fidarova E, Healy B, Rosenblatt E (2015) Need for radiotherapy in low and middle income countries - the silent crisis continues. Clin Oncol (R Coll Radiol) 27:107-114. https://doi.org/10.1016/j. clon.2014.10.006

Publisher's note Springer Nature remains neutral with regard to jurisdictional claims in published maps and institutional affiliations. 